\title{
KPI BUILDING BLOCKS FOR SUCCESSFUL GREEN TRANSPORT CORRIDOR IMPLEMENTATION
}

\author{
Gunnar Prause ${ }^{1}$, Meike Schröder ${ }^{2}$ \\ ${ }^{1}$ Tallinn University of Technology \\ School of Economics and Business Administration \\ Akadeemia Tee 3, 12618 Tallinn, Estonia \\ Gunnar.Prause@ttu.ee \\ ${ }^{2}$ Hamburg University of Technology \\ Institute of Business Logistics and General Management \\ Am Schwarzenberg-Campus 4, 21073 Hamburg, Germany \\ Meike.Schroeder@tuhh.de
}

\begin{abstract}
The green transport corridor concept represents a cornerstone in the development of integrated and sustainable transport solutions. Important properties of green corridors are their transnational character and their high involvement of large numbers of public and private stakeholders, including political level, requiring sophisticated approaches for implementation, management and governance. The current scientific discussion focusses on Key Performance Indicators (KPI) for monitoring and management of green transport corridor performance emphasizing the operational aspects.

The green corridor balanced scorecard approach tried to mitigate the strategic weakness of KPI concept by integrating cooperative and long-term views in order to come closer to a comprehensive green corridor control system. Until now all discussed KPI sets are too small and narrow for a successful implementation of green corridors so there is a need for the development of an useroriented model for green corridor control systems based on building blocks integrating existing KPI sets.

The building block approach for implementation has been successfully used for implementation and simulation in supply chain management. Based on these results the paper will present a holistic control system for successful implementation of green transport corridors based on building blocks integrating recent results about KPIs and balanced scorecards approaches. The research will empirically be verified by empirical results from European green corridor projects.
\end{abstract}

Keywords: green transport corridors, management control systems, networks, key performance indicators, corridor governance

\section{Introduction}

Green transport corridors (GTC) have gained attention in recent years and their main properties can be characterized as European trans-shipment routes with concentration of freight traffic between major hubs and relatively long distances of transport marked by reduced environmental and climate impact, while increasing safety and efficiency with application of sustainable logistics solutions, inter-modality, information and communication technology infrastructure, common and open legal regulations and strategically placed trans-shipment nodes. The theoretical foundations of GTC are related to sustainable aspects, multimodality, network and supply chain concepts (Hunke and Prause, 2013; Prause and Hunke, 2014).

Since the GTC concept was initiated by EU Commission within the Freight Transport Logistics Action Plan in 2007 and the EU White Paper on Transport in 2011 implementation of green transport corridor concepts was started in several EU-funded regional development projects in order to realise and compare different approaches and ideas of this concept (FTLAP, 2007; COM, 2011). One important aspect of implementations of GTC is the assessment and comparison of existing corridor concepts and monitoring and evaluation of GTC performance and development.

The current scientific discussion about performance monitoring of green corridors focusses on different sets of Key Performance Indicators (KPI) which are emphasizing operational and neglecting aspects but a general concept for a GTC management control systems, shortly called a green corridor controlling system (GCCS), is still missing (Prause, 2014). Another important shortcoming of the existing KPI approaches is related to their narrow scope restricting the KPI sets mainly to sustainable aspects.

Monitoring and assessment of business processes lead to different evaluation and measurement approaches where systems of KPI are considered to be an appropriate tool for organisational decision making, system control and performance assessment (Reichmann, 2001; Gladen, 2005; Parmenter, 2010). 
Popular KPI systems like DuPont system, balanced scorecard, ZVEI system, RL system, pyramid of ratios or tableau de bord are structured in forms of thematically grouped indicators which are called fields, sectors or perspectives (Brem et al., 2008). Such a thematic set of indicators will be called a KPI building block in this paper.

The current scientific discussion stresses different sets of KPI for monitoring and management of GTC mainly covering sustainable and operational aspects of the corridor performance (Hunke and Prause, 2013). Strategic aspects of KPI sets linked to network-orientation, infrastructural aspects or strategic risks are neglected (Prause, 2014; Schröder and Prause, 2015). A literature review reveals that only little research has been carried out on the role of GCCS, including building blocks of KPI for GTC and their relationship to the context of GTC implementation. For this reason, the paper tries to tackle this research gap by addressing the research questions what KPI building blocks might be important as components of a GCCS as well as for implementation of Green Transport Corridors, how they can be classified and how these building blocks are linked. The aim is to compile and construct KPI building blocks in the context of GCCS for the implementation and management of Green Transport Corridors and to point out the relationship of those building blocks.

In the remainder of the paper, at first the theoretical background is provided for Green Transport Corridor and their KPI systems. Afterwards, the research methodology for the empirical part is described. Since the paper resorts to empirical data of existing green transport corridor initiatives in the Baltic Sea region, the empirical results of the conducted expert interviews and workshops are presented. They show which building blocks of KPI might occur in the context of Green Transport Corridors.

\section{Literature Review}

\subsection{Management control systems and Green Transport Corridors}

Foundations of logistics and supply chain management control systems have been discussed by several scholars. In his work about competitive advantage Porter (1998) developed in the context of his value chain theory the importance of specific company activities and he stressed the specific profile of activities as source for the long-term competitive advantage of a company. These specific company activities which he used as synonyms for processes comprise also logistics and supply chain processes due to the cross-company character of value chains. These process-oriented aspects of logistics and supply chain issues have also been in the centre of the theoretical approach of Blum (2006) and Pfohl (2010) who proposed system and process theory as a fundament for logistical flow systems which comprise supply chains. Meanwhile, important management and controlling instruments for logistics process analysis and assessment like the SCOR model have proven the potency of the underlying process-oriented approach in supply chain management (Weber and Wallenburg, 2010).

Horvath (2011) pointed out that process orientation depicts an extension of the system approach and that logistics represents the flow perspective of the system approach which is in line with the view of Hahn (1999) who defines supply chain management as the "process- oriented interpretation of a company as activity centre". Based on these consideration Göpfert (2013) emphasized that logistics control system have to follow three global objectives, namely enhancement of effectivity, the increase of efficiency and the safeguarding of adaptability and viability of logistics management. A literature review about the appearance of KPIs in the context of logistics and supply chains leads to the issue of management control systems for supply chain, also called supply chain controlling (Weber, 2002; Göpfert, 2003, 2013; Jehle, 2005; Seuring and Müller, 2008).

By following Seuring (2006) is can be concluded that several supply chain controlling topics have been discussed by scholars but no integral theory or conceptual framework papers about supply chain controlling exist in the leading English speaking supply chain journals which contrasts to the German situation where different supply chain controlling concepts are deeply discussed explaining the dominance of references of German scholars in this field. Related KPI systems in German journal articles can be found in the context of logistics ratio systems as well as in supply chain balanced scorecards (Seuring and Müller, 2008; Göpfert, 2013; Prause, 2014).

KPI evaluate the performance or the success of structures or specific activities but the crucial point is to find and define the right KPIs which require a good understanding of the structure and the underlying processes together with their related key activities. The application of KPI approaches in business world often choose KPI according to a corresponding management framework like the DuPont system, the ZVEI system or the balanced scorecard (Reichmann, 2001; Gladen, 2005; Parmenter, 2010). The underlying sets of KPIs are ordered and grouped in sets of thematically related indicators reflecting related issues in certain 
business areas like sales, finance or logistics. These thematic sets of KPIs will be called in the sequel KPI building blocks and they represent in classical KPI systems sectors or perspectives (Brem et al., 2008).

Parmenter (2010) conducted a large empirical study about KPIs in public and private sectors and was able to define seven characteristics of effective KPIs:

- $\quad$ Non-Financial, i.e. KPI should represent non-financial measures

- $\quad$ Timely, i.e. KPI should be measured frequently

- Management focus, i.e. KPI should be acted upon by the management team

- Simple, i.e. all staff members are able to measure and correct if required

- Team-based, i.e. the KPI responsibility can be assigned to teams

- $\quad$ Significant impact, i.e. KPI should affect several critical success factors

- Limited dark side, i.e. the positive impact of KPI related actions must be safeguarded.

Since the findings of Parmenter are of general nature they also apply to supply chain management.

The GTC concept lies an emphasis is laid on a minimization of environmental impact, the creation of safe and sustainable logistics solutions by promoting trans-nationality and co-modality as well as on network concepts, Hunke and Prause (2013) pointed out that green SCM represents one important source for theoretical foundations since green SCM reveals interdependency between conventional SCM and ecoprograms (Sarkis, 2001; Prause and Hunke, 2014). In this understanding an important approach for the performance evaluation of GTC as well as for the comparison of existing Green Corridor implementations can be conducted by management control systems for supply chains comprising ecological aspects as well as the assessment of its international network environment by taking into account the international and cross-company aspects (Sydow and Möllering, 2009).

The current scientific discussion stresses different sets of Key Performance Indicators (KPI) for monitoring and management of green transport corridors by emphasizing green and operational aspects and neglecting infrastructural, strategic and network-oriented issues (Hunke and Prause, 2013). Consequently, Prause (2014) proposed a management control system in form of a Green Corridor balanced scorecard approach by integrating different sets of cooperative and network-oriented KPIs.

Schröder and Prause (2015) extended these existing considerations by adding risk management aspects from supply chain management to the Green Transport Corridor concept which makes it necessary to develop a comprehensive management control system, shortly called green corridor controlling system (GCCS), to safeguard an efficient, innovative, safe and environmental friendly implementation and longterm development for green transport corridors. Such a GCCS should comprise building blocks of KPIs as well as other important strategic controlling elements.

\subsection{Performance indicators and balanced scorecards for Green Transport Corridors}

An important breakthrough towards a holistic and consistent monitoring concept for multi-modal sustainable transport has been developed by the consortium of the EU-funded project "East-WestTransport-Corridor (EWTC2)" within the BSR Interreg IVB Programme, where for the first time a "Green Corridor Manual" based on the experiences and empirical evidences of the East-West-Transport-Corridor was presented including a KPI set for measuring different aspects of the performance of transport chains (Hunke and Prause, 2013). This KPI set can be separated into two subsets of indicators measuring enabling and operational criteria.

Table 1. Performance Indicators

\begin{tabular}{|l|l|l|}
\hline Performance areas & Operational indicators & Enabling indicators \\
\hline Economic efficiency & $\begin{array}{l}\text { Total cargo volumes } \\
\text { On time delivery }\end{array}$ & Corridor capacity \\
\hline Environmental efficiency & $\begin{array}{l}\text { Total energy use } \\
\text { Greenhouse gases, CO2e } \\
\text { Engine Standards } \\
\text { ISO 9001 dangerous goods }\end{array}$ & Alternative fuels filling stations \\
\hline Social efficiency & $\begin{array}{l}\text { ISO 31000 } \\
\text { ISO 39000 }\end{array}$ & $\begin{array}{l}\text { Safe truck parking } \\
\text { Common safety rating } \\
\text { Fenced terminals }\end{array}$ \\
\hline
\end{tabular}

Table 1 gives an overview about the KPIs which were selected from the East-West-TransportCorridor project and were also tested during the project duration. This set of KPIs has parallels in the economic and environmental areas with the proposed KPI set of the project "SuperGreen: Supporting EU's Freight Transport Logistics Action Plan on Green Corridors Issues" which was supported by the European 
Commission in the context of the $7^{\text {th }}$ Framework Programme and which has been launched between 2010 and 2013 in order to promote the development of European freight logistics in an environmentally friendly manner (SuperGreen, 2013). Additional or different KPI of the SuperGreen project are related to logistics processes within GTC, namely frequency, transport costs and transport time (EWTC, 2012).

EWTC separates among four key corridor stakeholders who are directly involved in the corridor performance, consisting of the corridor service providers, the transport service providers, the transport shippers and the infrastructure providers, i.e. regional or national governmental institutions. For all of these four key stakeholders characteristic performance indicators are specified (EWTC, 2012).

In addition to the KPI set the "Green Corridor Manual" proposes to use a corridor dashboard in order to connect the short-term KPIs and the enabling KPIs by visualizing capacity, accessibility and performance (EWTC, 2012). An important characteristic of the dashboard is that it is hub-oriented, i.e. that the dashboard depicts the main characteristics of the corridor hubs together with their infrastructural links. By doing so the dashboard consolidates already the logistics data to hub level, i.e. to meso level, and outlines the network situation of the corridor where the nodes represent the corridor hubs and the edges are the logistical links between them.

In this sense the dashboard visualises the size of the terminal or the hub, the number of modes of a terminal or a hub can serve, which can be between one and four modes, as well as the terminal capacity comprising:

- Opening hours

- Transit time

- Max number of lifts between rail and road

- Max number of container lifts

- Max number of arrivals and departures

- Max size of trains/vehicles/vessels

Under this consideration a dashboard represents a simple labelling system for the underlying green transport corridor infrastructure by linking and visualising relevant KPIs for operational control with enabling factors comprising capacity, redundancy and performance.

Table 2. Dashboard

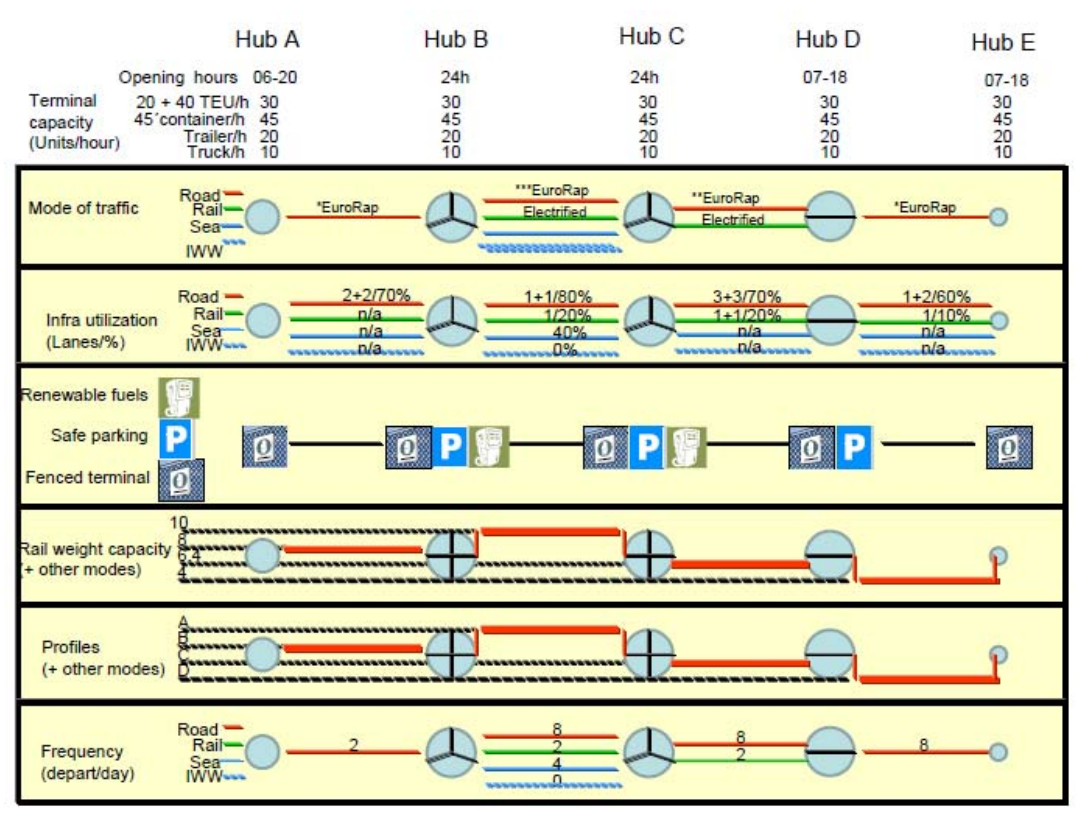

Thus, the dashboard stimulates improvements of the corridor infrastructure and facilitates the cooperation of all stakeholders along the corridor in order to improve total performance (EWTC, 2012).

But an approach based only on the KPI set together with the dashboard of the EWCT project is too narrow to cope with the requirements of a green corridor management control system which has to be taken under account the network and supply chain characteristics of a corridor so that flexible management control systems are needed which reflects the dynamic structures of a corridor as well as with the collective 
processes and strategies of the heterogeneous set of GTC stakeholders. Consequently, Weber (2002) developed a cross-company balanced scorecard for supply chains which keeps the two traditional perspectives of a balanced scorecard, namely the finance and process perspective, but he replaced other two traditional perspectives by two new ones, which he called cooperation intensity and cooperation quality, i.e. Weber's supply chain balanced scorecard comprised the financial perspective, the process perspective, the cooperation intensity and the cooperation quality (table 3 ).

Table 3. Weber's modified Supply Chain Balanced Scorecard (Source: Sydow and Möllering, 2009)

\begin{tabular}{|l|l|l|l|}
\hline Perspective & Strategic target & Indicator & Measures \\
\hline $\begin{array}{l}\text { Financial } \\
\text { perspective }\end{array}$ & Increase return of Supply Chain & $\begin{array}{l}\text { Increase RoA of Supply } \\
\text { Chain by } \%\end{array}$ & $\begin{array}{l}\text { Outsource warehousing } \\
\text { Reduce working capital }\end{array}$ \\
\cline { 2 - 4 } & Try to achieve cost leadership & $\begin{array}{l}\text { Recued logistics costs in } \\
\text { Supply Chain per unit by x\% }\end{array}$ & Bundling of partner capacities \\
\hline $\begin{array}{l}\text { Process } \\
\text { perspective }\end{array}$ & Max. lead time client: 10 days & $\begin{array}{l}\text { Reduce Supply Chain lead } \\
\text { time to 10 days }\end{array}$ & Cross partner process optimization \\
\cline { 2 - 4 } & $\begin{array}{l}\text { Increase flexibility of } \\
\text { operations }\end{array}$ & $\begin{array}{l}\text { Increase freezing point in \% } \\
\text { of lead time of Supply Chain }\end{array}$ & $\begin{array}{l}\text { Flexible parts, } \\
\text { Postponement }\end{array}$ \\
\hline $\begin{array}{l}\text { Perspective of } \\
\text { cooperation } \\
\text { intensity }\end{array}$ & $\begin{array}{l}\text { Increase data exchange between } \\
\text { Supply Chain partners }\end{array}$ & $\begin{array}{l}\text { Number and frequency of } \\
\text { exchanged data sets }\end{array}$ & $\begin{array}{l}\text { Improve IT - Networking of Supply } \\
\text { Chain Partners }\end{array}$ \\
\cline { 2 - 4 } & $\begin{array}{l}\text { Increase coordination between } \\
\text { Supply Chain partners }\end{array}$ & $\begin{array}{l}\text { Number of necessary } \\
\text { coordination meetings }\end{array}$ & $\begin{array}{l}\text { Systematic management of notes and } \\
\text { minutes }\end{array}$ \\
\hline $\begin{array}{l}\text { Perspective of } \\
\text { cooperation } \\
\text { quality }\end{array}$ & $\begin{array}{l}\text { Increase trust and satisfaction } \\
\text { Establish indicators for trust } \\
\text { and satisfaction }\end{array}$ & $\begin{array}{l}\text { Define common visions and } \\
\text { guidelines }\end{array}$ \\
\cline { 2 - 4 } & Increase cooperation quality & $\begin{array}{l}\text { Number of uncooperative } \\
\text { solved conflicts }\end{array}$ & $\begin{array}{l}\text { Establish "referee" for the Supply } \\
\text { Chain }\end{array}$ \\
\hline
\end{tabular}

Based on a Weber's concept for a supply chain balanced scorecard, Prause (2014) proposed a green corridor balanced scorecard by taking under account the empiric results of already existing green corridor projects. Accordingly, this green corridor balanced scorecard integrated the KPI sets for monitoring and management of Green Transport Corridors as well as cooperative and network-oriented concepts from supply chain management and has four perspectives (Table 4):

Table 4. Green Corridor Balanced Scorecard

\begin{tabular}{|l|l|}
\hline Sustainability perspective & $\begin{array}{l}\text { Economic efficiency } \\
\text { Environmental efficiency } \\
\text { Social efficiency }\end{array}$ \\
\hline Growth perspective & Innovation activities \\
& New services \\
& Green Corridor stakeholder fluctuation \\
& Turnover of new services \\
\hline Cooperation intensity & Data exchange \\
& Coordination needs \\
\hline Cooperation quality & Openness \\
& Trust level \\
& Transparency level \\
& Conflict level \\
\hline
\end{tabular}

This balanced scorecard includes all important perspectives for GTC and focusses on the underlying network properties of a corridor. Furthermore, it constitutes the KPI system of the EWTC2 project. The set of indicators is not complete and also the type of measurement and evaluation of the indicators is still open, but nevertheless the presented concept for a green corridor balanced scorecard is a further development and in line with a controlling concept for supply chains.

\subsection{Risk Management issues for Green Transport Corridors}

A consideration of the current management control systems and existing KPI systems for GTC reveals that they are emphasising sustainability, growth and inter-organizational cooperation aspects by neglecting risk issues which are related to the supply chain characteristics of a corridor (EWTC, 2012; Hunke and Prause, 2013; Prause, 2014). Already the multi-modal challenges within a GTC which are related to the green SCM issues to choose the right mode of transportation, to use the right equipment, and to use the right fuel have to consider risks related to costs, lead time, environmental performance and availability (Dekker et al., 2012). Consequently, a lot of risks with a negative impact on the supply chain may occur within the multi-modal transportation chains in GTC (Giunipero and Eltantawy, 2004). The 
multitude of actors integrated into transport services and GTC as well as their diversity even increases the number of potential risks.

Risks may have an influence on the flows of products, services, finance and information so that supply chain risk is "the damage - assessed by its probability of occurrence - that is caused by an event within a company, within its supply chain or its environment affecting the business processes of more than one company in the supply chain negatively" (Kersten et al., 2011). In order to cope with risks and to achieve corporate goals, it is necessary to implement risk management. Due to several corporate crises and insolvencies, specific pronouncements as well as regulatory requirements exist in numerous countries relating to the analysis, communication and monitoring of risks (Kajüter, 2003).

Schröder and Prause (2015) focused on risk identification and risk handling in the context of GTC. Based on the results of expert interviews the authors clustered the risks in main categories describing the sources of risks. The main categories were chosen in accordance with the three pillars of sustainability that are essential for the success of the GTC concept (Hunke and Prause, 2013). Consequently, the risks that might occur in each of the three main categories can be further differentiated into subcategories (Figure 1).

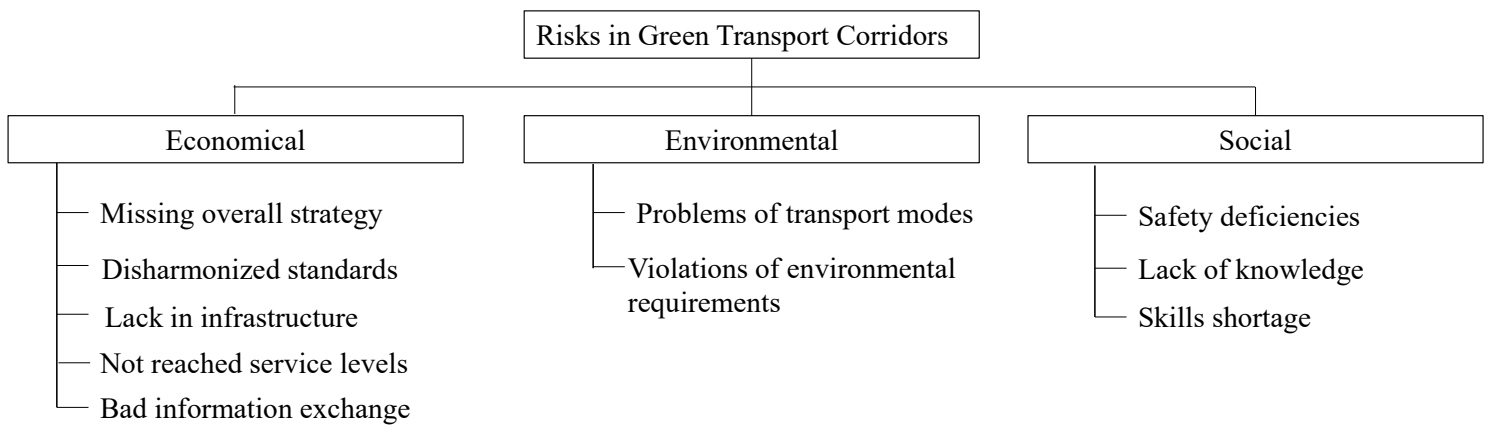

Figure 1. Risks in Green Transport Corridors

For risks regarding "economical" aspects Schröder and Prause (2015) proposed the five subcategories missing overall strategy, disharmonized standards, lack in infrastructure, not reached service level and bad information exchange. The second main category "environmental aspects" consists of the two subcategories problems of transport modes and violations of environmental requirements whereas the third main category "social risks" was divided by the authors into the three subcategories safety deficiencies, lack of knowledge and skills shortage. These risk categories are linked with operational and strategic issues of GTC and they are touching beyond economic, ecological and social topics also processoriented, growth and cooperation topics so that risks aspects are strongly linked to all parts of green corridor control system including a related KPI based performance measurement system.

In addition to these issues Christopher and Holweg (2011) emphasized the importance of volatility in SCM due to quickly and constantly changing global business environment in recent years so they argue that the assumption of stability no longer holds. Consequently, they presented an empirically composed supply chain volatility index and they proposed the use of key business parameters for volatility to be able to measure turbulences in supply chains and to adapt the supply chain structures. Weber et al. (2012) pointed out that supply chain volatility indicators arrived in the business world of SCM and they have to be considered in the context of KPIs due to their important role.

\subsection{Building Blocks for Green Transport Corridors}

Giannakis and Louis (2011) stressed that the high level of complexity of supply chains and the inherent risks that exist in both the demand and supply of resources - especially in economic downturns are recognized as major limiting factors in achieving high levels of supply chain performance. The use of modern information technology (IT) decision support systems is fast becoming an indispensable tool for designing and managing complex supply chain systems today. This paper develops a framework for the design of a multi-agent based decision support system for the management disruptions and mitigation of risks in manufacturing supply chains.

Building blocks are well known constructs in supply chain modelling and simulation. High competition enhances the strategic relevance of supply chain design together with the need for contingency 
plans to be able to deal with disruptions (Mourits and Evers, 1995). An important and cost-effective way to assess supply chain performance, to validate robust and reactive supply chain designs and to understand the dynamics of supply chains are simulation methods based on agent-based models (Manzini et al., 2005).

Lopez (2012) pointed out that supply chains are complex structures and agent-based simulation models are powerful enough to holistically evaluate supply chain complexity and its impact on performance as well as to understand the supply chain's structural and behavioural characteristics. His generic supply chain agent-based modelling is based on Supply Chain Building Blocks (SCBB) characterizing supply chain stakeholders as agents whose internal structure aligns with the SCOR management processes. The SCBB possess the capability to holistically assess the supply chain performance and for controlling the development of supply chain complexity across its structure. Existing methodologies for agent-based systematic modelling are founded on blocks to identify, define and specify the required information for the model in order to be able to execute the model for analysing the systems phenomena aiming to support the decision process of the stakeholder.

Relating to the high importance of process orientation of SCM mentioned by Hahn (1999) special attention should be dedicated to the process perspective in the context of performance measurement. Performance metrics are required to be able to describe and understand the complexity and the properties of the underlying processes for supply chains. Such metrics in form of KPI systems aim to support the ontime assessment of emergent behaviour, as well as the later analysis for identifying complexity's causes and effects on performance (Lopez, 2012). For this reason logistics performance indicators have been discussed intensively in scientific literature and lists of logistics related KPI systems which are used in theory and practice have been published (Reichmann, 2001; Weber, 2002; Weber et al., 2012).

Göpfert (2013) presented an empirically founded list of 80 logistics performance indicators with a short list of outstanding logistics KPIs to control logistics processes and to benchmark logistics performance. This short list of outstanding KPIs includes average inventory in days, logistics service degree (lead time, reliability, readiness, flexibility), share of logistics costs per total costs. Thematically grouped sets of KPIs will be called in the sequel KPI building blocks and they enjoy all properties of performance metrics in supply chain management.

It has to be kept in mind that the overall goal of the supply chain KPI system is the effective and efficient management of all activities associated with the flow and transformation of goods from raw materials to the final product to be delivered to the end customer (Milgate, 2001). The performance of these goals is assessed by looking into the system's characteristics reflected in the metrics affected by complexity (Seuring et al., 2004). Since all these considerations also apply to GTC due to their underlying supply chain structures.

\section{KPI building blocks for Green Transport Corridors}

\subsection{Research Questions and Design}

It is not the aim of this paper to focus on KPI building blocks which only have an effect on one company but to also look at KPI building blocks for the entire GTC concept. Therefore, the research questions are:

RQ 1: What kind of KPI building blocks might be relevant for the implementation of a GTC?

RQ 2: How are these KPI building blocks related and how can they be ordered?

RQ 3: Which role play the KPI building blocks in the context of a GCCS?

This study targets at KPI building blocks for the implementation of GTC, based on the literature review and the identified research gap. In addition, the gained KPI building blocks will be investigated according to their relationship. Finally, the KPI building blocks will be ordered and their role within a comprehensive GTC control system will be discussed. For these purposes, the research design constitutes as follows: The empirical evidence in this paper is based on the qualitative research style (Blaxter et al., 2006).

Here, the complexity of the research question requires personal interviews and a qualitative approach. The willingness to answer questions in a greater depth and in an open discussion can only be achieved by personal and individual conversations with selected interview partners. Furthermore, performance assessment addresses a sensitive issue. Hence, it is of great importance to build trust with the different stakeholders. 
The authors conducted case studies, expert interviews and workshops between 2006 and 2013 within several national and European projects comprising the BSR projects LogOn Baltic, EWTC II and BSR Transportcluster to get a better understanding of the risks that might occur during transport services in general and in supply chains within GTC (Schröder and Prause, 2015). For this, surveys, interviews and workshops that have been conducted by the authors during the European projects together with corridor managers, transport service providers, shippers and infrastructure provider have been analysed.

\subsection{Identification of KPI building blocks for Green Transport Corridor implementation}

The definition of the right KPIs requires a good understanding of the structure and the underlying processes together with their related key activities. The KPI approaches in business world often choose indicator sets according to a corresponding management framework and order these sets of KPIs into thematic groups of indicators reflecting related issues, processes or sub-systems like in well-known ratio systems or balanced scorecards (Reichmann, 2001; Gladen, 2005; Parmenter, 2010).

Thus, in different workshops, surveys and interviews the experts were asked about success factors for GTC implementation and which indictors for a comprehensive performance measurement of a GTC might include. Since the interviews took place during different projects and in different contexts the results lead to different sets of indicators like mentioned already in the part of the literature review. By combining the empiric results with other results from the literature review it is possible to highlight eight thematic sets of performance indicators for GTC implementation comprising finance, sustainability in three dimensions, logistics processes, cooperation intensity and quality, growth, risks as well as the infrastructural dashboard.

In accordance with the results of the EWTC project it should consider that these eight thematic sets of indicators are related to four different views of the key corridor stakeholders so that the underlying sets of KPI can differ in structure and composition among the stakeholders. A visualization of these KPI building blocks leads to figure 2 .

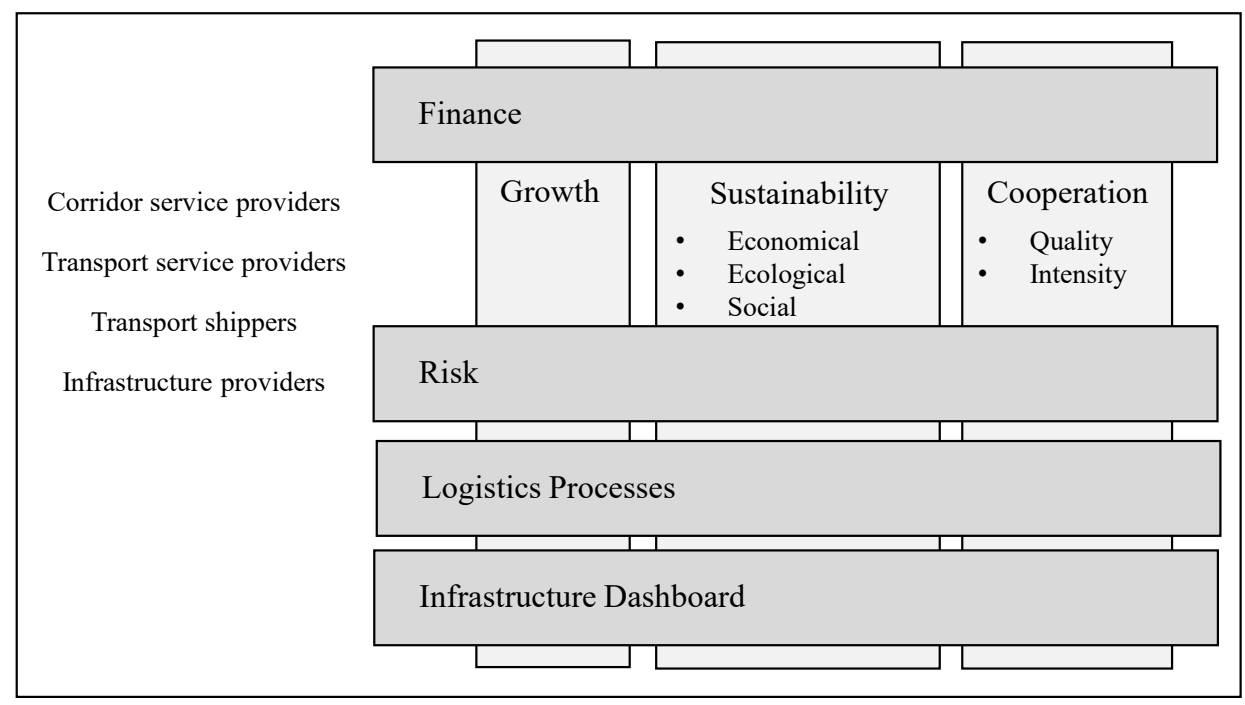

Figure 2. KPI building blocks for Green Transport Corridors

All these building blocks appear four times due to the fact that there are four key corridor stakeholders so that for each key stakeholder exists a specific layer yielding a cube or a brick structure of this KPI-system.

\subsection{Performance indicators for implementation of Green Transport Corridors}

The KPI building blocks frame only the thematic groups for the performance indicators which have to measure current status of a GTC. Based on the literature review together with the results of the empirical activities a set of KPI for each building block shall be discussed by considering already established indicators. For each presented indicator it has to be stressed that the final set of performance indicators has to be specified in accordance with the needs of the type of corridor stakeholder. The largest list of KPIs exists in the case of the EWTC project for the transport service providers (EWTC, 2012; table 6). 
Table 6. Tentative Performance indicators for transport service providers

\begin{tabular}{|c|c|c|}
\hline Tentative Performance Indicators & Unit & Building Block \\
\hline Total goods volume & Tons, Tons/year & Economic Sustainability \\
\hline On time delivery / Reliability & Number $\& \%$ of on time services & Economic Sustainability / Process \\
\hline Corridor ability and capacity & $0 / 1$ & Economic Sustainability \\
\hline Used capacity & $\%$ of used corridor capacity & Economic Sustainability / Process \\
\hline Energy use & $\mathrm{KWh}, \mathrm{KWh} / \mathrm{tkm}$ & Ecologic Sustainability \\
\hline $\mathrm{GHG}, \mathrm{CO} 2 \mathrm{e}$ & Tons, $\mathrm{g} / \mathrm{tkm}$ & Economic Sustainability \\
\hline Engine standards & Number, \% & Ecologic Sustainability \\
\hline ISO 9001dg & $0 / 1$ & Ecologic Sustainability \\
\hline Alternative fuels filling stations & Number, \#/1000 km & Ecologic Sustainability \\
\hline ISO 31000 & $0 / 1$ & Social Sustainability \\
\hline ISO 39000 & $0 / 1$ & Social Sustainability \\
\hline Fenced terminals used & $0 / 1$ & Social Sustainability \\
\hline Safe parking use & $0 / 1$ & Social Sustainability \\
\hline Innovation activities & $\%$ innovative companies & Growth \\
\hline New services & \# per year & Growth \\
\hline Green corridor stakeholder fluctuation & $\%$ of stakeholders & Growth \\
\hline TO of new services & $\%$ of TO & Growth \\
\hline Availability of qualified workforce & $\%$ open jobs by qualification level & Growth / Risk \\
\hline Data exchange & \# exchanged data sets & Cooperation Intensity \\
\hline Coordination needs & \# coordination meetings & Cooperation Intensity \\
\hline Openness & Openness indicator & Cooperation Quality \\
\hline Trust level & Trust indicator & Cooperation Quality \\
\hline Transparency level & Transparency indicator & Cooperation Quality \\
\hline Conflict level & \# uncooperative solved conflicts & Cooperation Quality \\
\hline Transport costs & $€ / \mathrm{tkm}$ & Process / Finance \\
\hline Frequency & \# services per day/week & Process \\
\hline Lead time & \# of days & Process / Financial sustainability \\
\hline Return on Assets & Return/TO per assets & Financial \\
\hline Logistics costs & Logistics costs per total costs & Finance / Economic sustainability \\
\hline Readiness & $\%$ immediately delivered services & Process / Economic sustainability \\
\hline Quality & $\%$ of complains of delivered services & Process/ Risk / Economic sustainability \\
\hline Flexibility & $\%$ fulfilled special services & Process / Economic sustainability \\
\hline Cargo bundling & $\%$ bundled transports & Economic sustainability \\
\hline Strategy implementation & \# of open strategic aims and enabling criteria & Risk/ Growth / Economic sustainability \\
\hline Disharmonized standards & \# used standards & Risk / Cooperation Quality \\
\hline Lack in Infrastructure & \# hot spots in dashboard & Risk / Process / Economic sustainability \\
\hline info exchange failures & $\%$ of info exchanges & Risk / Cooperation Intensity \\
\hline Accidents & \# accidents & Risk, Growth \\
\hline Theft and crime & Numbers & Risk \\
\hline Knowledge level & \# of human caused disruptions of SC & Risk/ Growth \\
\hline Environmental violations & \# per year & Risk / Economic Sustainability \\
\hline Volatility & Volatility indicators & Risk \\
\hline
\end{tabular}

This list of tentative performance indicators is not complete but it represents the majority of the most important KPIs from literature review and empirical measures. The discussed performance indicators are linked to one or more thematic build blocks underpinning figure 1.

\section{Conclusion and Implications}

Green Transport Corridors are imbedded into an international network environment composed of different stakeholders acting along a defined geographical area in order to achieve their different goals within the frame of common corridor objectives. This requires new concepts and instruments for multidimensional assessment of collective strategies and processes by taking into account international and cross-company aspects. Network-oriented management control systems for GTC are still in evolution due to their underlying dynamic structures and their high complexity (Sydow and Möllering, 2009; Prause and Hunke, 2014).

A literature review revealed that KPI sets play an important role in the frame of GCCS but the existing approaches are too narrow for a successful implementation and management of corridors. Consequently, the paper proposes the use of KPI building blocks in the context of GCCS due to wide scope and higher flexibility of building blocks. The thematic focusses of the different building blocks are covered by KPI and the building blocks are linked by semantic intersections. Nevertheless the use of performance indicators for GTC is related to several open questions touching the frame conditions (Prause and Hunke, 2014). 
Firstly, it has to be mentioned that the green corridor KPI are reflecting the situation on corridor level so that underlying data from stakeholder level must be collected and aggregated to corridor level. Both tasks, collection and aggregation, are not clarified until now since transparency of sensible stakeholder data as well as specifications for calculations of consolidation of values are still open. Prause and Hunke (2014) even point out that sensible internal company data are protected by corridor stakeholders.

Another open question is related to the fact that even all data would be available and even aggregation procedures for calculating corridor indicators from stakeholder data would be feasible a problem of delimitation still exists. A GTC integrates different stakeholders along a certain limited geographical area which can be described as a tubular service cluster so that logistics services between destinations outside the corridor which are using only parts of the corridor have to be taken into account for performance assessments. But how to delimit the performances and how to get the necessary data from companies outside the corridor are fully open.

Under these considerations the research open new directions towards the performance assessment of GTC and the discussed KPI building blocks represent a step forward in the evolution of green transport controlling systems. Furthermore the building blocks are pathing the way for the use of simulation in green transport corridors since they represent the link to agent based corridor simulation. For the development of a green corridor simulation platform based on building blocks more research is needed. Also the connection of KPI building blocks and existing corridor governance models have to further investigated since each governance model is linked with specific thematic emphasises.

Reference (German titles translated by the authors)

1. Blaxter, L., Hughes, C., and Tight, M. (2006) How to Research, $3^{\text {rd }}$ ed. Berkshire: Open University Press.

2. Blum, H. (2006). Logistics Controlling. Wiesbaden: Dt. Universitätsverlag.

3. Brem, A.; Kreusel, N.; Neusser, C. (2008) Performance measurement in SMEs: literature review and results from a German case study. International Journal of Globalisation and Small Business, 2(4), 411-427. DOI: 10.1504/IJGSB.2008.018102

4. Christopher, M.; Holweg, M. (2011) Supply Chain 2.0: managing supply chains in the era of turbulence. International Journal of Physical Distribution and Logistics Management, 41(1), 63-82, DOI: $10.1108 / 09600031111101439$.

5. COM (2011). Roadmap to a Single European Transport Area - Towards a competitive and resource efficient transport system. Commission of European Communities. Brussels, 28.03.2011.

6. Dekker, R.; Bloemhof, J.; Mallidis, I. (2012) Operations Research for green logistics - An overview of aspects, issues, contributions and challenges. European Journal of Operational Research, 219 (3), 671-679, DOI 10.1016/j.ejor.2011.11.010.

7. EWTC. (2012) Green Corridor Manual - Task 3B of the EWTC II project.

8. FTLAP. (2007) Communication from the Commission: Freight Transport Logistics Action Plan. Commission of European Communities. Brussels, 18.10.2007.

9. Göpfert, I. (2013) Logistics, 3rd ed., München: Franz Vahlen.

10. Giannakis, M.; Louis, M. (2011). A multi-agent based framework for supply chain risk management, Journal of Purchasing and Supply Management, 17(1), 23-31. DOI 10.1016/j.pursup.2010.05.001.

11. Giunipero, L.C. and Eltantawy, R.A. (2004) Securing the upstream supply chain: a risk management approach. International Journal of Physical Distribution \& Logistics Management, 34 (9), 698-713. DOI 10.1108/09600030410567478.

12. Gladen, W. (2005) Performance Measurement - Controlling mit Kennzahlen. $3^{\text {rd }}$ ed. Wiesbaden: Gabler-Verlag.

13. Hahn, D. (1999). Thesis for the future of procuring within an integrated supply chain management. In: Hahn, D.; Kaufmann, L. (eds.): Handbook of industrial supply management, Wiesbaden: Gabler, 851855.

14. Horvath, P. (2011) Controlling, 12th ed., Munich: Vahlen.

15. Hunke, K.; Prause, G. (2013) Management of Green Corridor Performance. Transport and Telecommunication, 14(4), 292-299. DOI 10.2478/ttj-2013-0025.

16. Jehle, M. (2005) Value-oriented Supply Chain Management und Supply Chain Controlling. Frankfurt: Lang.

17. Kajüter, P. (2003) Risk management in supply chains. In: Seuring, S., Müller, M., Goldbach, M., and Schneidewind, U. (eds.), Strategy and Organization in Supply Chains, Heidelberg: Physica, 321-336. 
18. Kersten, W., Hohrath, P., Böger, M., and Singer, C. (2011) A Supply Chain Risk Management Process. International Journal of Logistics Systems and Management, 8 (2), 152-166. DOI: 10.1504/IJLSM.2011.0386

19. Lopez, A. (2012) Agent Based Simulation Approach to assess Supply Chain Complexity and its Impact on Performance, Lohmar: EUL.

20. Manzini, R.; Ferrari, E.; Gamberi, M.; Persona, A.; Regattieri, A. (2005) Simulation performance in the optimisation of supply chain. Journal of Manufacturing Technology Management, 16(2), 127-144. DOI 10.1108/17410380510576796.

21. Milgate, M. (2001) Supply chain complexity and delivery performance: an international exploratory study. Supply Chain Management: An International Journal, 6(3), 106-118. DOI 10.1108/13598540110399110.

22. Mourits, M.; Evers, J. (1995) Distribution Network Design: An integrated planning support framework. International Journal of Physical Distribution and Logistics Management, 25(5), 43-57. DOI 10.1108/09600039510089703.

23. Parmenter, D. (2010) Key performance indicators: Developing, implementing, and using winning $K P I s, 2^{\text {nd }}$ ed. Hoboken: John Wiley \& Sons.

24. Pfohl, H. (2010) Logistics systems, $8^{\text {th }}$ ed., Berlin: Springer.

25. Porter, M.E. (1998) On competition. Boston: Harvard Business School Publishing.

26. Prause, G. (2014). A Green Corridor Balanced Scorecard. Transport and Telecommunication, 15(4), 299-307. DOI 10.2478/ttj-2014-0026.

27. Prause, G.; Hunke, K. (2014) Secure and Sustainable Supply Chain Management: Integrated ICTSystems for Green Transport Corridors. Journal of Security and Sustainability Issues, 3(4), 5-16. DOI 10.9770/jssi.2014.3.4(1)

28. Reichmann, T. (2001) Controlling with performance indicators and management reports. $6^{\text {th }}$ ed. Munich: Vahlen

29. Sarkis, J. (2001) Introduction. Greener Management International, 35(3), 21-25.

30. Schröder, M.; Prause, G. (2015) Risk Management for Green Transport Corridors. Journal of Security and Sustainability Issues, 4(4), forthcoming.

31. Seuring, S., Goldbach, M.; Koplin, J. (2004) Managing time and complexity in supply chains: two cases from the textile industry. International Journal of Integrated Supply Management, 1(2), 180198. DOI 10.1504/IJISM.2004.004864.

32. Seuring, S. (2006) Supply Chain Controlling: summarizing recent developments in German literature. Supply Chain Management: An International Journal, 11(1), 10-14. DOI 10.1108/13598540610642420.

33. Seuring, S.; Müller, M. (2008) From literature review to a conceptual framework for sustainable supply chain management. Journal of Cleaner Production, 16 (15), 1699-1710. DOI 10.1016/j.jclepro.2008.04.020.

34. SuperGreen (2013) SuperGreen. Available at http://www.supergreenproject.eu, (15/08/04).

35. Sydow, J.; Möllering, G. (2009) Production in networks, 2nd ed., Munich: Franz Vahlen.

36. Weber, J. (2002) Logistics and Supply Chain Controlling, $5^{\text {th }}$ edition, Stuttgart: Schäffer-Poeschel.

37. Weber, J.; Wallenburg, C. (2010) Logistics and Supply Chain Controlling, $10^{\text {th }}$ ed., Stuttgart: SchäfferPoeschel.

38. Weber, J.; Wallenburg, C.; Bühler, A.; Singh, M. (2012) Logistics Controlling with ratio systems, BVL/Otto Beisheim School of Management, Koblenz: Görres-Druckerei. 